\title{
Simultaneous cell growth and ethanol production from cellulose by an engineered yeast consortium displaying a functional mini-cellulosome
}

\author{
Garima Goyal ${ }^{2}$, Shen-Long Tsai ${ }^{1,2}$, Bhawna Madan ${ }^{1}$, Nancy A DaSilva ${ }^{3}$ and Wilfred Chen ${ }^{{ }^{*}}$
}

\begin{abstract}
Background: The recalcitrant nature of cellulosic materials and the high cost of enzymes required for efficient hydrolysis are the major impeding steps to their practical usage for ethanol production. Ideally, a recombinant microorganism, possessing the capability to utilize cellulose for simultaneous growth and ethanol production, is of great interest. We have reported recently the use of a yeast consortium for the functional presentation of a minicellulosome structure onto the yeast surface by exploiting the specific interaction of different cohesin-dockerin pairs. In this study, we engineered a yeast consortium capable of displaying a functional mini-cellulosome for the simultaneous growth and ethanol production on phosphoric acid swollen cellulose (PASC).

Results: A yeast consortium composed of four different populations was engineered to display a functional minicellulosome containing an endoglucanase, an exoglucanase and a $\beta$-glucosidase. The resulting consortium was demonstrated to utilize PASC for growth and ethanol production. The final ethanol production of $1.25 \mathrm{~g} / \mathrm{L}$ corresponded to $87 \%$ of the theoretical value and was 3 -fold higher than a similar yeast consortium secreting only the three cellulases. Quantitative PCR was used to enumerate the dynamics of each individual yeast population for the two consortia. Results indicated that the slight difference in cell growth cannot explain the 3-fold increase in PASC hydrolysis and ethanol production. Instead, the substantial increase in ethanol production is consistent with the reported synergistic effect on cellulose hydrolysis using the displayed mini-cellulosome.

Conclusions: This report represents a significant step towards the goal of cellulosic ethanol production. This engineered yeast consortium displaying a functional mini-cellulosome demonstrated not only the ability to grow on the released sugars from PASC but also a 3-fold higher ethanol production than a similar yeast consortium secreting only the three cellulases. The use of more complex cellulosomal structures may further improve the overall efficiency for ethanol production.
\end{abstract}

Keywords: cellulose, cellulosome, ethanol, yeast, consolidated bioprocessing

\section{Background}

It has been estimated that 1.3 billion mega-tons (dry weight) of terrestrial plants are produced annually on a world-wide basis [1]. Due to its renewable, abundant, and sustainable nature, lignocellulosic biomass is the only feedstock to potentially substitute for fossil fuels. Ethanol, which is generally expected to be the first major commercial product of this emerging cellulosic biofuel technology,

\footnotetext{
* Correspondence: wilfred@udel.edu

'Department of Chemical Engineering, University of Delaware, Newark, DE 19716, USA

Full list of author information is available at the end of the article
}

has great potential to lessen our country's dependency on fossil fuel [2].

Unfortunately, the recalcitrant nature of cellulosic materials and the high cost of enzymes required for efficient hydrolysis are the major limiting steps to the more widespread exploitation of this natural resource [3]. Consolidated bioprocessing (CBP), which combines the production of enzymes, hydrolysis of cellulose, and fermentation of glucose and xylose to ethanol in one reactor, is gaining increasing recognition as a potential breakthrough for cellulosic ethanol production as up to a four-fold reduction in cost can be potentially achieved
Ciomed Central

() 2011 Goyal et al; licensee BioMed Central Ltd. This is an Open Access article distributed under the terms of the Creative Commons Attribution License (http://creativecommons.org/licenses/by/2.0), which permits unrestricted use, distribution, and reproduction in any medium, provided the original work is properly cited. 
$[2,4]$. An ideal microorganism for CBP should possess the capability of efficient enzyme production and simultaneous cellulose saccharification and ethanol fermentation. Saccharomyces cerevisiae is an attractive candidate because of its high ethanol productivity and inherent ethanol tolerance [5]. In recent years, attempts have been made to engineer $S$. cerevisiae for cellulose hydrolysis under anaerobic conditions with only varying degrees of success [6-8].

Cellulosomes are naturally occurring elaborate enzyme complexes found in many anaerobic microorganisms that can efficiently hydrolyze cellulose based on the high level of enzyme-substrate synergy [9]. The synergistic effects are due to (1) the targeting effect of the cellulose binding module, (2) the proximity effect of the enzymes, and (3) the elimination of substrate inhibition from the quick uptake of glucose. We have recently reported the use of a yeast consortium for the functional presentation of a mini-cellulosome structure onto the yeast surface by exploiting the specific interaction of the different cohesin-dockerin pairs employed [10]. We demonstrated not only the feasibility and flexibility of the consortium system, but also the benefit of mini-cellulosomes to facilitate ethanol production. Unfortunately, direct ethanol production from phosphoric acid swollen cellulose (PASC) was achieved only using resting-cell cultures and the feasibility of simultaneous growth and ethanol production had not been demonstrated. In this paper, we demonstrate for the first time the use of this synthetic yeast consortium for direct growth and ethanol production from PASC, an important first step toward the ultimate goal of CBP. Quantitative polymerase chain reaction (qPCR) was used to investigate the dynamics of the individual populations during fermentation.

\section{Results and discussion}

Surface display of the mini-scaffoldin Scaf-ctf using the constitutive Ag $\alpha 1$ anchor system

To enable the direct growth and ethanol production on PASC by the synthetic yeast consortium, the Aga1-Aga2 anchor system used in the previous study [10] which required galactose for induced expression was replaced by a constitutively expressed Ag $\alpha 1$ anchor system using a strong PGK promoter (Figure 1A). In addition, the entire expression cassette was transferred to a CEN/ARS-based plasmid (YCplac33-AG $\alpha$-scaf3) containing the centromeric sequence to ensure a constant copy number and improved protein expression. This plasmid was subsequently transformed into S. cerevisiae strain BY4742, which was then denoted as strain SC.

To demonstrate the display of Scaf-ctf, immunofluorescence assays were carried out using the anti C-myc antibody (Figure 1B). A detectable fluorescence signal was observed for over $85 \%$ of cells, which is higher than the
$60 \%$ observed for cells using the Aga1-Aga2 anchor system. This improved percentage of surface display can be attributed to the improved plasmid stability using the CEN/ARS-based plasmid and the reported superior display efficiency of the Ag $\alpha 1$ anchor system [11].

\section{Growth and ethanol production from PASC}

The ability of the consortium to grow and produce ethanol directly from PASC was investigated. In addition to the newly constructed strain displaying Scaf-ctf (SC) under a constitutive promoter, three other strains secreting either an endoglucanase (AT), an exoglucanase (CB) or a $\beta$-glucosidase (BF) tagged with a different dockerin domain and flanked by a His6 tag used in the consortium were as described before (Table 1) [10]. Different yeast strains were initially grown separately in SDC medium overnight and then mixed in the optimized ratio $(7: 2: 4: 2)$ to a total initial cell density of $8 \times 10^{6} \mathrm{cell} / \mathrm{ml}$ to form the functional consortium (C1) [12]. A strain carrying the plasmid pCEL15 (CE) with no heterogenous protein expression was used as a control population (Table 1). To compare the performance, two other consortia composed of either only the Scaf-ctf-displaying cells (SC) and CE (C2) or cellulase-secreting cells $(\mathrm{AT} / \mathrm{CB} / \mathrm{BF})$ and $\mathrm{CE}(\mathrm{C} 3)$ at the same ratio as $\mathrm{C} 1$ were used. All consortia developed are depicted in Figure 2.

An initial glucose concentration of $0.2 \mathrm{~g} / \mathrm{L}$ was added to allow the synthesis and assembly of the cellulosome structure. For the consortium $\mathrm{C} 2$ containing only SC, no appreciable level of cell growth and PASC degradation was observed; only the added glucose was converted to ethanol (Figure 3A and 3B). In comparison, a significant level of cell growth was observed for the consortium $\mathrm{C} 1$ containing the functionally displayed cellulosome, and only minimum growth was detected for the consortium C3 secreting only cellulases (Figure 3A). The enhancement in cell growth was also reflected in both PASC degradation and ethanol production; the final ethanol level of $1.25 \mathrm{~g} / \mathrm{L}$ is 3 -fold higher than the consortium secreting only cellulases (Figure 3B). The final ethanol yield of $0.43 \mathrm{~g}$ ethanol/g PASC is equivalent to $87 \%$ of the theoretical value. Even though the ethanol productivity is much lower than required in practice [13], our results successfully demonstrated the concept of using a microbial consortium for the simultaneous growth and ethanol production from cellulose. However, further improvements of the consortium system are required to significantly improve the overall productivity.

\section{Verification of mini-cellulosome assembly}

Whole cell fluorescence measurements were undertaken to verify and quantify the assembly of secreted cellulases onto the cell surface. Cells were harvested after fermentation and washed three times with buffer before probing 


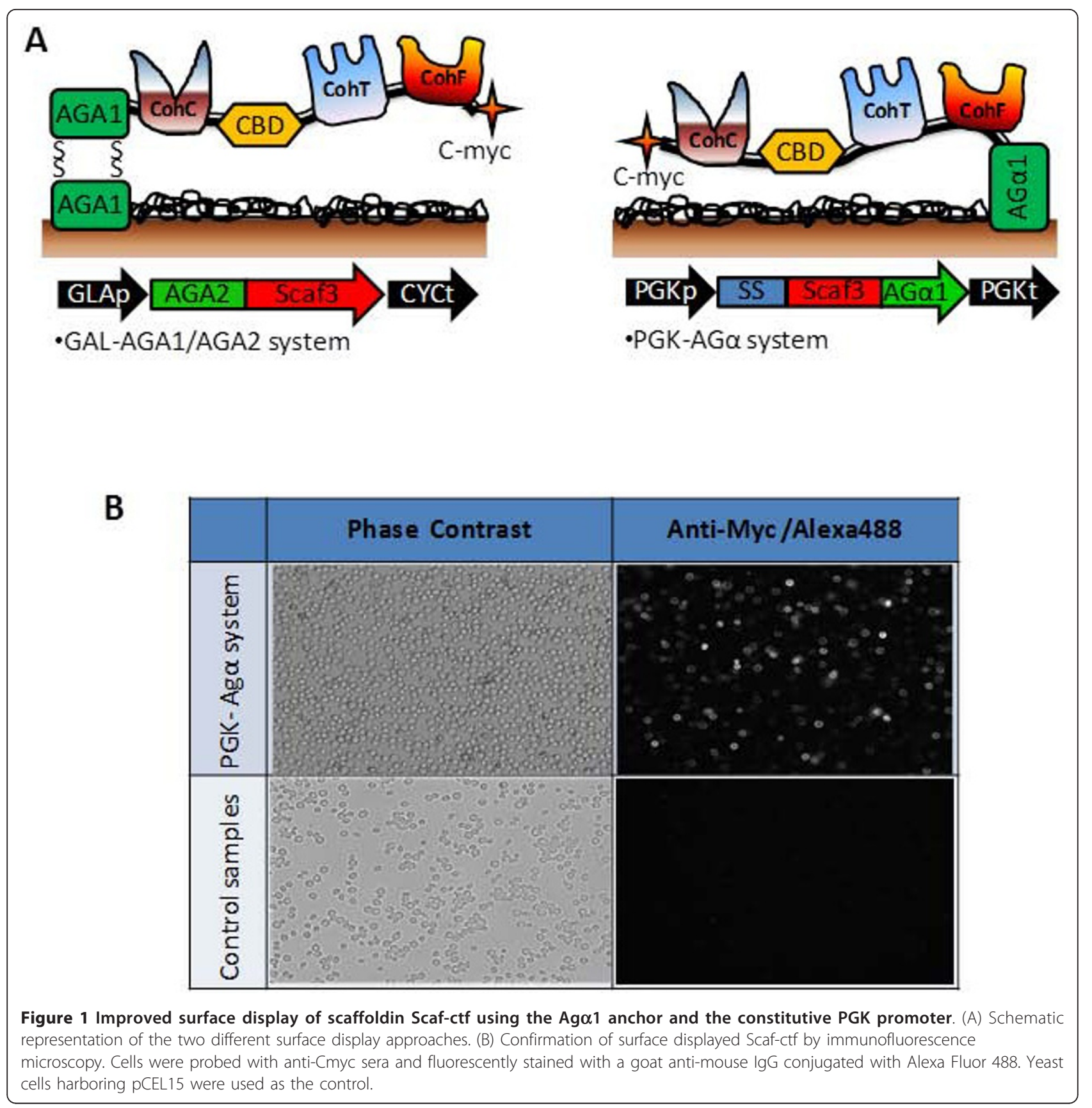

Table 1 Strains and plasmids used in this study

\begin{tabular}{llll}
\hline Strain & Plasmid & Phenotype & Source \\
\hline CE & pCEL15 & Secretes a small peptide (negative control) & Tsai et al, 2010 \\
AT & pAt & Secretes the endoglucanase At (CelA from C. thermocellum with its native dockerin) & Tsai et al, 2010 \\
CB & pCBH2C & Secretes the cellobiohydrolase CBHc (CBHII from T. reesei fused with a dockerin from C. cellulolyticum) & Tsai et al, 2010 \\
BF & pBGLf & Secretes the $\beta$-glucosidase Bglf (Bg1l from T.aurantiacus fused with a dockerin from R. flavefaciens) & Tsai et al, 2010 \\
SC & pAg $\alpha$-scaf3 & Display of Scaf-ctf by an Aga 1 anchor in a centromeric plasmid & This study \\
\hline
\end{tabular}

S. cerevisiae strain BY4742 was used in all cases. 

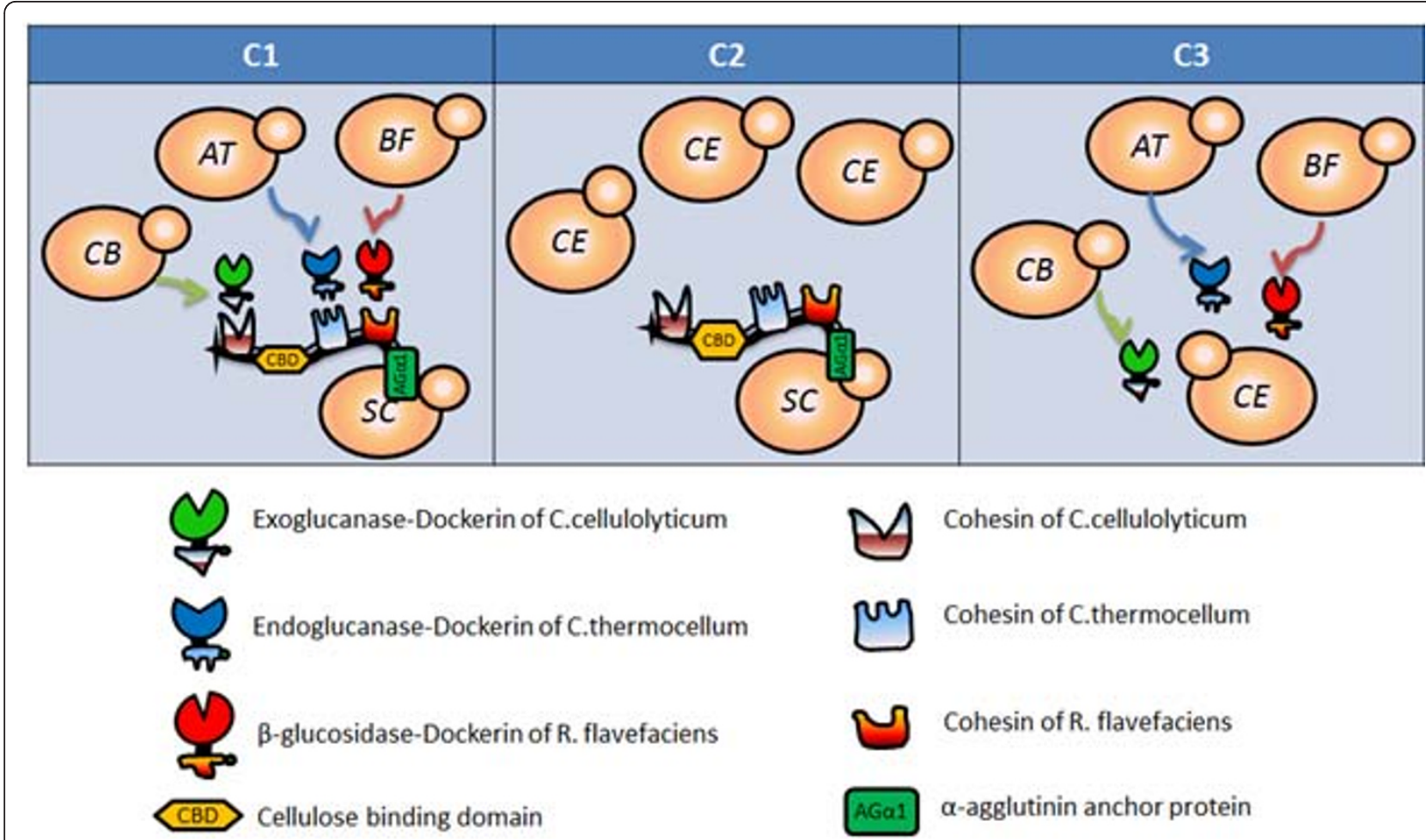

Figure 2 A schematic of the different consortia used in this study

with both anti-Cmyc (Scaf-ctf) and anti-His antibodies (his tagged cellulases). As shown in Figure 3C, the correct assembly of the mini-cellulosome was observed only for consortium $\mathrm{C} 1$, which showed an appreciable level of whole-cell fluorescence toward both antibodies, indicating the simultaneous display of Scaf-ctf, and docking of cellulases. In contrast, fluorescence was detected only with the Cmyc antibody for consortium C2 displaying only Scaf-ctf and only background levels of fluorescence were observed with consortium C3 (Figure 3C). These results are significant as they demonstrate, for the first time, that a synthetic consortium can be successfully engineered for the functional display of cellulosomes for cellulosic ethanol production in a CBP-like setting.

\section{Dynamics of the yeast consortium by qPCR}

To gain a better understanding of the synthetic yeast consortium, qPCR was used to probe the dynamics of all four yeast populations during fermentation. Primers (Table 2) were designed to target a $\sim 250$ bp region of a unique gene of each population coding for either the endoglucanase (AT), the exoglucanase (CB), the $\beta$-glucosidase (BF), or the displayed Scaf-ctf (SC). Total DNA was individually extracted from the four different populations and a linear standard curve spanning three-log concentrations from $10^{4}$ to $10^{6} \mathrm{cell} / \mathrm{ml}$ was generated under optimized conditions (Data not shown). Using the qPCR method, cell growth was clearly demonstrated for all four populations during fermentation (Figure 4). However, the final cell density increased by over 3-fold for the strain displaying the functional mini-cellulosome (SC), while roughly a 2fold increase was observed for the other three populations. This difference in the growth rates is consistent with other reports indicating that the use of a ternary celluloseenzyme-microbe complex (SC) yields much higher rates of cellulose utilization than using only a cellulose-enzyme complex (AT, $\mathrm{CB}$, and $\mathrm{BF})$ [14]. It is interesting to note that strains secreting enzymes $(\mathrm{AT}, \mathrm{CB}, \mathrm{BF})$ were growing at slightly different rates probably a result of dissimilar levels of metabolic burden due to expression of different cellulases. Even with the differences in growth, the final population ratio of $7: 1.8: 3.4: 1.9$ did not change significantly from the initial inoculation ratio. It should be noted that the growth curve obtained using the qPCR method was in $90 \%$ agreement with the results obtained from direct cell counting, indicating the validity of the qPCR method to rapidly track the temporal dynamics of the individual population during fermentation.

Similarly, the dynamics of consortium C3 secreting only cellulases was probed using qPCR (Figure 4). Again, all three enzyme-secreting strains (AT, $\mathrm{CB}$, and $\mathrm{BF}$ ) were shown to grow during the fermentation. Although cell growth for all three strains was slower than in consortium $\mathrm{C} 1$, the total final cell density of the three strains 

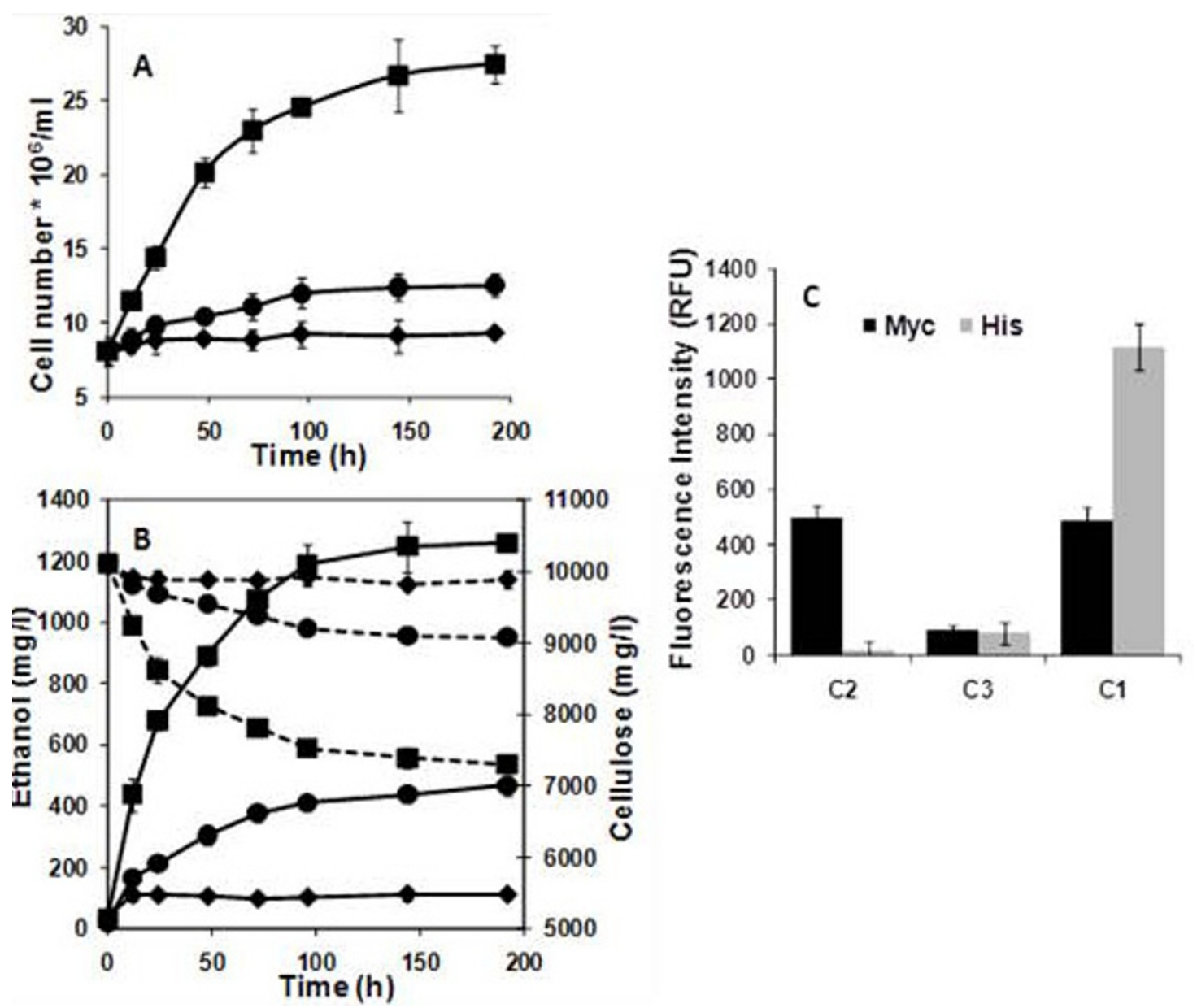

Figure 3 Cell growth and ethanol production by the cell consortia. (A) Cell growth and (B) PASC hydrolysis (dotted line) and ethanol production (solid line) by the different yeast consortia, i.e., consortium C2 without secreting enzymes ( $)$ ), consortium C3 only secreting enzymes $(\bullet)$ and consortium C1 forming the cellulosome structure (-). (C) Surface display of the mini-cellulosome was probed with either anti-C-myc sera for the displayed scaffoldin or anti-C-His6 sera for the three cellulases docked on the scaffoldin and fluorescently stained with a goat anti-mouse IgG conjugated with Alexa Fluor 488. Whole cell fluorescence was determined using a fluorescent microplate reader. Data shown are the mean values ( \pm standard deviation) obtained from 3 independent experiments.

Table 2 Primers used in this study

\begin{tabular}{|c|c|c|}
\hline Primers & Sequence $\left(5^{\prime}-3^{\prime}\right)$ & Relevance \\
\hline PgkFp & CCGCCATGGTGTTTGCAAAAAGAACAAAACTG & Subcloning of Ag $\alpha$-Scaf \\
\hline PgkRp & CCGCCATGGCCCTATGCGGTGTGAAATACC & Subcloning of Ag $\alpha$-Scaf \\
\hline Fxba1-Sctf & GCGCTCTAGAGGCGATTCTCTTAAAGTTACAGT & Subcloning of Ag $\alpha$-Scaf \\
\hline ScafFP & GCGCCAAAAGCTCTITTATCTCAACC & qPCR \\
\hline ScafRP & CCACATCACTAATCACTTCTGATGTGGTG & $\mathrm{qPCR}$ \\
\hline AtFP & GCAGAATGGGAAGACTGGAAGAGC & $\mathrm{qPCR}$ \\
\hline AtRP & CCGCCGTCATGACTTGTAACATTGTTG & qPCR \\
\hline CBHIIFP & CGCAAAGGTTCCCTCTTTTATGTGGC & qPCR \\
\hline CBHIIRP & TCCGGATATCGGAATATTCCACGACAA & qPCR \\
\hline BglfFP & ATCATGGCGGCCTITTACAAGGTTG & qPCR \\
\hline BglfRP & ССTCTCCAAAAACTCCGGTGAACTTTC & qPCR \\
\hline
\end{tabular}



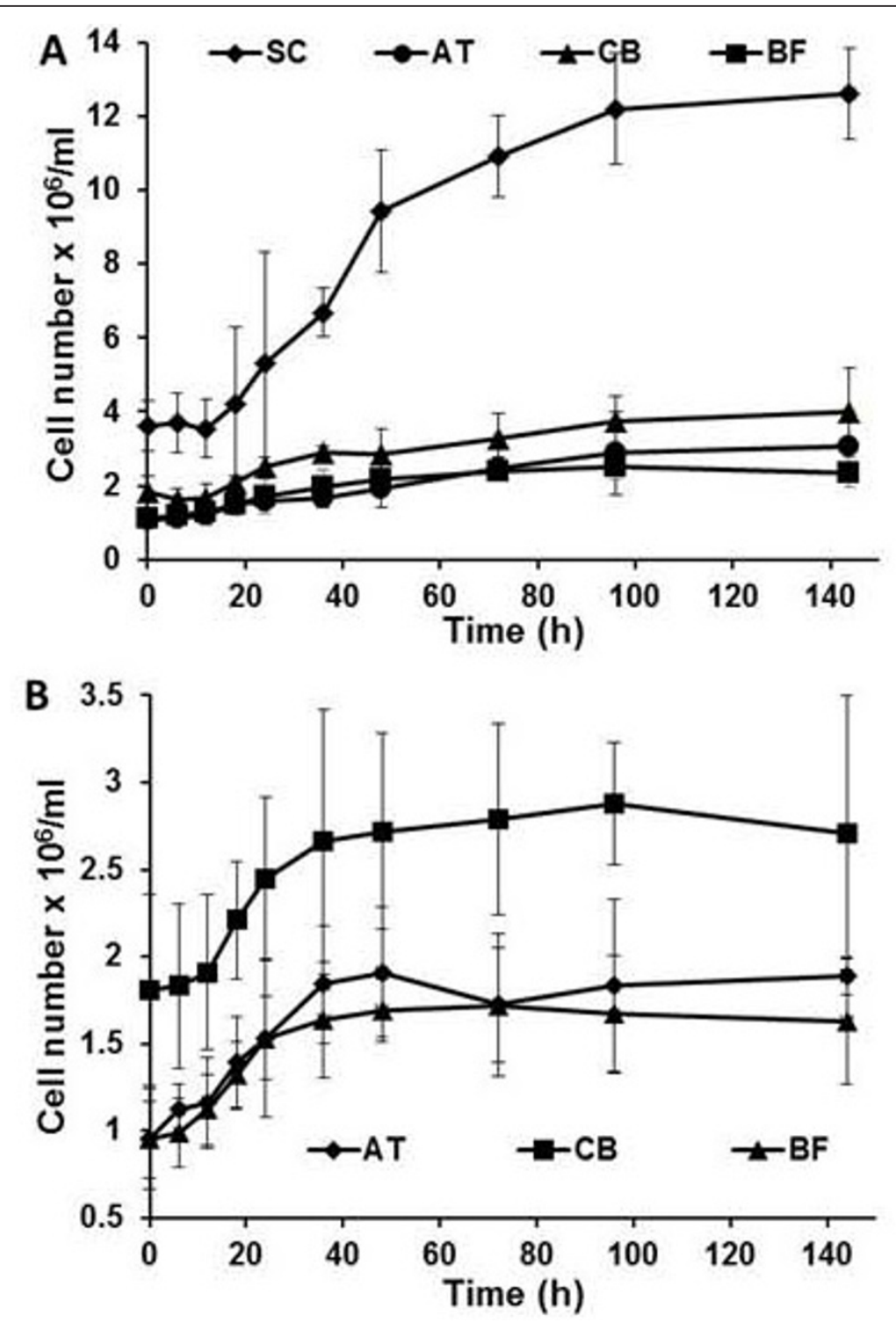

Figure 4 Growth dynamics of individual populations in (A) consortium C1 that could form cellulsosome structure and (B) consortium C3 that can only secret enzymes. Changes in cell number of individual yeast populations were probed by qPCR. Data shown are the mean values ( \pm standard deviation) obtained from 3 independent experiments.

was $\sim 85 \%$ of that of consortium $\mathrm{C} 1$. This slight reduction in the cell density cannot explain the observed 3-fold difference in PASC hydrolysis and ethanol production. Instead, the substantial increase in ethanol production is consistent with our previously reported synergistic effect on cellulose hydrolysis using the displayed mini-cellulosome structure when compared with free enzymes [10].

\section{Conclusions}

In this era of high energy demand, there is an urgent need to develop new cost-effective methods that can convert complex cellulosic biomass into simple sugars and eventually ethanol. Our group has recently mimicked the natural anaerobic cellulose degradation mechanism by displaying a mini-cellulosome on the yeast surface and observed a similar synergistic effect on cellulose hydrolysis and ethanol production compared to free enzymes [10,12]. To accomplish the goal of simultaneous cell growth and ethanol production on cellulose, we engineered a yeast consortium capable of the surface assembly of a functional mini-cellulsome via intercellular complementation. The resulting consortium can grow on cellulose and produce ethanol more efficiently than a similar consortium secreting only cellulases because of the synergistic action on cellulose hydrolysis by the mini-cellulosome structure. Although the level of ethanol production is relative 
modest, this is a promising first step toward the goal of CBP using an engineered yeast consortium. Further improvements in the overall productivity necessitate the use of more complex cellulosome structures as in natural anaerobic microorganisms. The flexibility of the consortium design offers the possibility of displaying more complex cellulosomes by manipulating the individual population involved in the consortium.

\section{Methods}

\section{Strains, plasmids, and media}

Escherichia coli strain JM109 [recA1 end A1 supE44 hsdR17 gyrA96 thi, relA1, $\lambda^{-1} \Delta$ (lac-proAB) F traD36 proAB lacIqZ DM15] was used as a host for genetic manipulations. Cells were grown in LB medium (5 g/l yeast extract, $10 \mathrm{~g} / \mathrm{l} \mathrm{NaCl}, 10 \mathrm{~g} / \mathrm{l}$ tryptone) supplemented with ampicillin $(100 \mathrm{mg} / \mathrm{l})$ when required. S. cerevisiae strain BY4742 (MAT $\alpha$ his $3 \Delta 1$ leu $2 \Delta 0$ lys $2 \Delta 0$ ura3 $\Delta 0$ ) was used for displaying the scaffoldin and secretion of cellulases. The phenotypes and sources of the yeast strains and plasmids that were used in this study are listed in Table I. Yeast strains were routinely cultured in SDC medium (20 g/l dextrose, $6.7 \mathrm{~g} / 1$ yeast nitrogen base, and $5 \mathrm{~g} / \mathrm{l}$ casamino acids) at $30^{\circ} \mathrm{C}$ on a rotary shaker at $250 \mathrm{rpm}$.

\section{Construction of YCplac33-AG $\alpha$-Scaf3 for constitutive surface-display of Mini-scaffoldin Scaf-ctf}

A centromeric plasmid, YAG $\alpha$-Scaf3, used for surface display of the trifunctional mini-scaffoldin Scaf-ctf, was constructed as described below. All primers used in cloning are given in Table 2. The Scaf-ctf fragment, consisting of three different cohesins from Clostridium cellulolyticum, Clostridium thermocellum and Ruminococcus flavefaciens and a cellulose binding module (CBM), was amplified from the plasmid pSctf [10] by PCR using primers FXba1Sctf and Sctf-Sal1R. The resulting fragment (2046 bps) was digested with $X b a 1$ and Sal1 and cloned into the $X b a 1$ and Sal1 sites of a multiple copy surface-display vector pSSAG $\alpha$, which consisted of the yeast 3-phosphoglycerate kinase (PGK1) promoter, the secretion signal of Rhizopus oryzae amylase, a C-myc tag, the C-terminus $\alpha$ agglutinin gene AG $\alpha 1$ and the PGK1 terminator. The resulting plasmid was named pAG $\alpha$-Sctf. The entire expression cassette encoding the PGK promoter to the PGK terminator was then amplified from plasmid pAG $\alpha$ Sctf by PCR using primers PgkFp and PgkRp. The PCR product obtained was then subcloned into the $S m a 1$ site of the CEN/ARS-based vector YCplac33 via blunt end ligation after kinase treatment. Transformants were confirmed by restriction digestion and named YCplac33AG $\alpha$-scaf3. The YCplac33-AG $\alpha$-scaf3 plasmid was transformed in S. cerevisiae BY4742 using the standard lithium acetate procedure [15].

\section{Anaerobic fermentation}

PASC was prepared as described by Walseth from Avicel PH101 (Sigma) [16]. For anaerobic fermentation, different consortia were grown in rubber stoppered glass serum bottles containing SC-PASC medium $(6.7 \mathrm{~g} / \mathrm{l}$ yeast nitrogen base w/o amino acids, $20 \mathrm{~g} / \mathrm{l}$ casamino acids, and $10 \mathrm{~g} / \mathrm{l}$ PASC supplemented with $10 \mathrm{mM} \mathrm{CaCl}_{2}, 0.01$ $\mathrm{g} / \mathrm{l}$ ergosterol and $0.42 \mathrm{~g} / \mathrm{l}$ tween 80 ). Precultures of each yeast population were grown separately in SDC media (20 g/l glucose, $6.7 \mathrm{~g} / \mathrm{l}$ yeast nitrogen base, $5 \mathrm{~g} / \mathrm{l}$ casamino acids), harvested, and washed with sterile water to prevent media carry over. For co-culturing of the synthetic consortia, each strain was mixed initially in the optimized ratio to a total optical density of 0.8 . Samples were collected periodically through a capped syringe needle pierced through the bottle stopper [12]. Yeast cells in fermentation media were counted in triplicate on SDC plates by the plate count method.

\section{Reducing sugar and ethanol assays}

Reducing sugars were measured by the DNS method. Samples were collected periodically and mixed immediately with equal amount of DNS reagents $(10 \mathrm{~g} / \mathrm{l}$ dinitrosalicylic acid, $10 \mathrm{~g} / \mathrm{l}$ sodium hydroxide, $2 \mathrm{~g} / \mathrm{l}$ phenol, $0.5 \mathrm{~g} / \mathrm{l}$ sodium sulfite) and incubated for 5 to $15 \mathrm{~min}$ at $95^{\circ} \mathrm{C} .1 \mathrm{ml}$ of $40 \%$ Rochelle salts was added to fix the color before measuring the absorbance at $575 \mathrm{~nm}$ using a spectrophotometer. The glucose concentration was determined by using a Sigma HK assay kit. For measuring the amount of unhydrolyzed cellulose, the phenol-sulfuric acid method described by Dubois et. al. was used [17]. Ethanol concentration was measured using a gas chromatograph (model 6890, Hewlett Packard, USA) with a HP-FFTP column and a flame ionization detector (FID) detector.

\section{Immunofluorescence assay}

Immuno-fluorescence microscopy was done as described previously [10]. In short, cells were washed with PBS (phosphate buffered saline) and resuspended in PBS containing $1 \mathrm{mg} / \mathrm{ml}$ BSA (bovine serum albumin). Either antiHis 6 or anti-Cmyc antibody were added and incubated at room temperature for $1 \mathrm{~h}$ on a rotary shaker. After washing, AlexaFluor ${ }^{\mathrm{TM}} 488$ - conjugated anti-mouse secondary antibody was added. Cells were then washed three times with PBS buffer and resuspended in PBS buffer mixed with $1 \mathrm{mg} / \mathrm{ml} \mathrm{BSA}$. Whole-cell fluorescence images were obtained using a fluorescence microscope (Olympus BX51) with an excitation wavelength at $485 \mathrm{~nm}$ and an emission wavelength at 535 .

\section{Real time quantitative PCR}

Total DNA from each strain was extracted using the High Pure PCR Template Preparation Kit (Roche Applied Science, Germany), and the concentration was determined 
using a Nano-drop spectrophotometer at 260/280 nm. All primers used for PCR reactions are listed in Table II. Quantitative PCR assays were done in $25 \mu$ final volumes containing $2 \mu \mathrm{l}$ DNA template, $0.2 \mu \mathrm{M}$ each respective primer, and $12.5 \mu \mathrm{l}$ of SYBR Green Master Mix (Fisher Scientific). All amplifications were carried out in optical grade 96 well plates from Bio-rad with an initial step at $95^{\circ} \mathrm{C}$ for $3 \mathrm{~min}$ followed by 40 cycles of $95^{\circ} \mathrm{C}$ for $15 \mathrm{~s}, 57^{\circ} \mathrm{C}$ for 1 min, $72^{\circ} \mathrm{C}$ for $30 \mathrm{~s}$. All samples were triplicated in culture and analysis. To quantify the individual yeast population, a standard curve was generated for each individual cell population by ten-fold dilutions from $10^{6} \mathrm{CFU} / \mathrm{ml}$ to $10^{4} \mathrm{CFU} / \mathrm{ml}$.

\section{Abbreviations}

CBM: cellulose binding module; CBP: consolidated bioprocessing; FID: flame ionization detector; PASC: phosphoric acid swollen cellulose; PBS: phosphate buffered saline; PCR: polymerase chain reaction; qPCR: quantitative polymerase chain reaction.

\section{Acknowledgements}

This research was supported by grants from NSF (CBET 0903894) and DOE (EE0000988).

\section{Author details}

'Department of Chemical Engineering, University of Delaware, Newark, DE 19716, USA. ²Department of Chemical and Environmental Engineering, University of California, Riverside, CA 92521, USA. ${ }^{3}$ Department of Chemical Engineering and Materials Science, University of California, Irvine, CA 92697, USA.

\section{Authors' contributions}

WC developed the idea for the study. WC, ND and ST design the research. GG and ST did the literature review and prepared the manuscript. ST and BM constructed the vectors. GG did the majority of the lab work, cultivations and enzyme essays. Figures were prepared by GG and ST. WC and ND supervised the study, and participated in the design and coordination and helped to revise the manuscript. All authors read and approved the final manuscript.

\section{Competing interests}

The authors declare that they have no competing interests.

Received: 7 September 2011 Accepted: 1 November 2011

Published: 1 November 2011

\section{References}

1. Demain AL, Newcomb M, Wu JHD: Cellulase, clostridia, and ethanol. Microbiol Mol Biol Rev 2005, 69:124-154.

2. Lynd LR, van Zyl WH, McBride JE, Laser M: Consolidated bioprocessing of cellulosic biomass: an update. Curr Opin Biotechnol 2005, 16:577-583.

3. Himmel ME: Biomass recalcitrance: engineering plants and enzymes for biofuels production. Science 2007, 316:982-982.

4. van Zyl WH, Chimphango AFA, den Haan R, Görgens JF, Chirwa PWC: Nextgeneration cellulosic ethanol technologies and their contribution to a sustainable Africa. Interface Focus 2011, 1:196-211.

5. Nevoigt E: Progress in metabolic engineering of Saccharomyces cerevisiae. Microbiol. Mol Biol Rev 2008, 72:379-412.

6. Den Haan R, Rose SH, Lynd LR, van Zyl WH: Hydrolysis and fermentation of amorphous cellulose by recombinant Saccharomyces cerevisiae. Metab Eng 2007, 9:87-94.

7. Jeon E, Hyeon JE, Suh DJ, Suh YW, Kim SW, Song KH, Han SO: Production of cellulosic ethanol in Saccharomyces cerevisiae heterologous expressing Clostridium thermocellum endoglucanase and Saccharomycopsis fibuligera beta-glucosidase genes. Mol Cells 2009, 28:369-373.
8. Yanase S, Yamada R, Kaneko S, Noda H, Hasunuma T, Tanaka T, Ogino C, Fukuda $\mathrm{H}$, Kondo $\mathrm{A}$ : Ethanol production from cellulosic materials using cellulase-expressing yeast. J Biotechnol 2010, 5:449-455.

9. Bayer EA, Lamed R, Himmel ME: The potential of cellulases and cellulosomes for cellulosic waste management. Curr Opin Biotechnol 2007, 18:237-245.

10. Tsai SL, Goyal G, Chen W: Surface Display of a Functional Minicellulosome by Intracellular Complementation Using a Synthetic Yeast Consortium and Its Application to Cellulose Hydrolysis and Ethanol Production. Appl Environ Microbiol 2010, 76:7514-7520.

11. Kotrba P, Ruml T: Surface Display of Metal Fixation Motifs of Bacterial P1Type ATPases Specifically Promotes Biosorption of $\mathrm{Pb} 2+$ by Saccharomyces cerevisiae. Appl Environ Microbiol 2010, 76:2615-2622.

12. Tsai SL, Oh J, Singh S, Chen RZ, Chen W: Functional Assembly of Minicellulosomes on the Saccharomyces cerevisiae Cell Surface for Cellulose Hydrolysis and Ethanol Production. Appl Environ Microbiol 2009, 75:6087-6093.

13. Zaldivar J, Nielsen J, Olsson L: Fuel ethanol production from lignocellulose: a challenge for metabolic engineering and process integration. Appl Microbiol Biotechnol 2001, 56:17-34.

14. Lu YP, Zhang YHP, Lynd LR: Enzyme-microbe synergy during cellulose hydrolysis by Clostridium thermocellum. P Natl Acad Sci USA 2006, 103:16165-16169.

15. Ausubel FM, Brent R, Kingston RE, Moore DD, Seidman JG, Smith JA, Struhl K: Current Protocols in Molecular Biology. New York: John Wiley \& Sons; 19942.

16. Walseth CS: Occurrence of cellulases in enzyme preparations from microorganisms. TAPPI J 1952, 35:228-233.

17. Dubois M, Gilles KA, Hamilton JK, Rebers PA, Smith F: Colorimetric method for determination of sugars and related substances. Anal Chem 1956, 28:350-356.

doi:10.1186/1475-2859-10-89

Cite this article as: Goyal et al:: Simultaneous cell growth and ethanol production from cellulose by an engineered yeast consortium displaying a functional mini-cellulosome. Microbial Cell Factories 2011 10:89.

\section{Submit your next manuscript to BioMed Central and take full advantage of:}

- Convenient online submission

- Thorough peer review

- No space constraints or color figure charges

- Immediate publication on acceptance

- Inclusion in PubMed, CAS, Scopus and Google Scholar

- Research which is freely available for redistribution

Submit your manuscript at www biomedcentral.com/submit
C Biomed Central 